\title{
RECRYSTALLIZATION OF HIGH SYMMETRY ALUMINIUM SINGLE CRYSTALS AFTER PLANE STRAIN COMPRESSION
}

\author{
A.AKEF ${ }^{*}$, R.FORTUNIER $^{* *}$, J.H.DRIVER ${ }^{*}$ and T.WATANABE ${ }^{\neq}$ \\ * Materials Department, Ecole des Mines de Saint-Etienne, France \\ ** UNIREC, Firminy, France \\ $\neq$ Department of Materials Science, Faculty of Engineering, Tohoku University, \\ Sendai, Japon
}

\begin{abstract}
Recrystallization textures have been correlated with the initial deformation textures and microstructures of 3 high symmetry orientations of aluminium crystals deformed in plane strain compression up to true strains of 1,5 and annealed at $400^{\circ} \mathrm{C}$. The deformation textures were characterised by $\mathrm{X}$-ray pole figures and the recrystallized grain orientations by SACP. The initial orientations were chosen to provide different types and spatial distributions of potential nucleation sites in the form of high lattice misorientation regions.
\end{abstract}

In the case of 2 of the orientations, the recrystallization textures could be derived from the initial deformation textures by means of the $30-40^{\circ}<111>$ orientation relationship characteristic of oriented growth. These orientations, $\{111\}<112>$ and $\{110\}<011>$ do not appear to form large numbers of transition bands.

However, during plane strain compression, the $\{001\}<010>$ cube orientation splits into many $\{012\}<021>$ bands misoriented by large rotations of opposite sign about TD. Subsequent recrystallization develops a strong cube texture, probably as a consequence of oriented nucleation from the relatively high density of cube oriented nuclei in the residual transition band regions. It is concluded that the controlling mechanism of recristallization texture development-oriented growth or oriented nucleation-depends upon the initial grain orientation.

\section{INTRODUCTION}

The aim of the present work is to correlate the deformation microstructures of 3 selected crystal orientations of aluminium with the subsequent recrystallized grain orientations in terms of current theories of grain nucleation and growth $[1,4]$. The orientations are chosen to provide a variety of deformation heterogeneities :

(i) the cube $\{001\}<010>$ orientation which develops a large number of transition bands separating strongly misoriented deformation bands [5]. 
(ii) the $\{111\}<11 \overline{2}>$ orientation which forms only 1 transition band between $\mathrm{Cu}$ and Goss components effectively creating a quasi-bicrystal $[6,7]$.

(iii) the $\{011\}<01 \overline{1}>$ orientation which is relatively stable during deformation but leads to a very wide $\mathrm{X}$-ray diffraction peaks indicating local misorientations.

\section{EXPERIMENTAL}

Oriented aluminium single crystals of $99,996 \%$ purity (principal impurities $\mathrm{Cu}$, $\mathrm{Fe}, \mathrm{Si}, \mathrm{Mg}$ ) were deformed in channel die compression to logarithmic strains of 0,25 to 1,5. The experimental details are described in [7]. The initial specimen dimensions were typically length $\sim 12 \mathrm{~mm}$, width $5 \mathrm{~mm}$, thickness $5 \mathrm{~mm}$. After strains $>0,15 \mathrm{X}$-ray pole figures from areas of $\sim 2$ to $4 \mathrm{~mm}^{2}$ on the compression surface were used to characterise the grain orientations.

Annealing experiments were carried out at 250 and $400^{\circ} \mathrm{C}$. Results are described here only for the cases of low $(\sim 0,2)$ and high $(\sim 1)$ strains after $10 \mathrm{~h}$ at $400^{\circ} \mathrm{C}$, i.e. at the end of primary recrystallization. After annealing grain orientations were determined individually by selected area channelling patterns (SACP). The orientations of all the grains on one complete compression surface of the recrystallized materiai were determined to provide a detailed description of the texture, spatial grain distributions and, ultimately, the grain boundary misorientations. Some SACP textures were checked with $\mathrm{X}$-ray pole figures.

The reference system used in the following is $X_{1}=$ transverse (TD), $X_{2}=$ elongation direction $(\equiv R D)$ and $X_{3}=$ compression plane normal $(\equiv N D)$.

\section{RESULTS}

The overall results described here are briefly summarised in Table 1.

Table 1 : Summary of annealing results on deformed Al crystals

\begin{tabular}{|c|c|c|l|}
\hline Initial orientation & Strain & $\mathrm{N}^{\circ}$ rec. grains & \multicolumn{1}{|c|}{ Recrystallization textures } \\
\hline$(001)[010]$ & 0,25 & 1 & $\begin{array}{r}\text { No recrystallization - recovery } \\
\text { cube }+2 \text { minor components } \\
\text { rotated } 35^{\circ} \text { about }<111>\end{array}$ \\
\hline$(111)[11 \overline{2}]$ & 0,25 & 16 & $\sim$ Random \\
& 0,7 & 321 & $(111)[01 \overline{1}]$ texture \\
\hline$(011)[01 \overline{1}]$ & 0,25 & 44 & $\sim$ Random \\
& 1 & 202 & $\sim(032)[22 \overline{3}]+(023)[\overline{2} 3 \overline{2}]$ \\
\hline
\end{tabular}




\subsection{Cube $\{001\}<010>$ orientation}

Up to a critical strain of $\sim 0,25$ the cube orientation deforms homogeneously and then splits into 2 orientations by lattice rotations of opposite sign about the transverse $\mathrm{X}_{1}$ axis, Figure 1a. These orientation changes take place in deformation bands aligned in the $\mathrm{X}_{2}$ direction, of width $\sim 50-100 \mu \mathrm{m}$, and distributed almost periodically in the width $\mathrm{X}_{2} \mathrm{X}_{3}$ plane. At a strain of $\sim 1$ the bands (essentially of single slip) approach the $\{049\}$ $<094>$ orientations. The narrow regions between the bands are transition bands with residual cube orientations. The slip modes, lattice rotations and spatial distributions of the bands have been analyzed in detail by Akef and Driver [5].

On annealing at $400^{\circ} \mathrm{C}$ the cube crystal deformed to $\varepsilon=0,25$, i.e. just before the onset of transition band formation, did not recrystallize (Table 1). After a strain of 1 when orientation splitting has occurred, recrystallization develops a relatively large number of small grains with a pronounced cube texture, Figure 1b. According to recent models of oriented nucleation from transition bands [8,9], cube oriented nuclei grow out from the near cube regions of the transition bands between the rotated bands. The (001)[010] crystal develops a high density of such transition bands and thus strongly favours oriented nucleation as a texture controlling mechanism. The predominant cube texture of this deformed and recrystallized crystal is therefore consistent with nucleation from transition bands. However Figure $1 \mathrm{~b}$ also shows the presence of 2 minor texture components formed by a $35^{\circ}$ rotation about 2 of the $<111>$ directions (dashed lines). This suggests some influence of oriented growth. According to the latter mechanism grain boundaries with a $30-40^{\circ}<111>$ relationship between certain growing grains and deformed matrix have a rapid growth rate so that by rate selection these special grains can occupy a relatively large volume fraction of the recrystallized material.

The overall results on the deformed cube crystal are therefore consistent with oriented nucleation from a high density of cube oriented transition bands with, nevertheless, a small tendency for some oriented growth.

\section{$3.2(111)[11 \overline{2}]$ orientation}

As shown by [6,7], this crystal splits into two orientations by rotations of opposite sign about $\mathrm{TD}$, separated by a unique transition band region in the centre of the sample (in the $X_{1} X_{3}$ plane). One side rotates towards Goss (110)[00i] and the other towards $\mathrm{Cu}$ (112)[11i] so that the transition band has the characteristics of a tilt boundary of misorientation $\sim 55^{\circ}$ after a strain $>0,5$, Figure $2 \mathrm{a}$.

Annealing after a low strain 0,25 , insufficient to develop an obvious transition band, leads to a recrystallized structure composed of a few large grains with almost random texture. After a strain of 0,7 annealing then leads to a strong (111)[011] recrystallization texture, Figure $2 \mathrm{~b}$, related to the original orientation by $30^{\circ}$ rotation about [111]. This strongly suggests that nucleation occurs in the transition region and that grains growing out in both directions adapt the $30^{\circ}<111>$ relation with the "average" deformed matrix, i.e. that recrystallization of this orientation is completely dominated by oriented growth.

\section{$3.3(011)[01 \overline{1}]$ orientation}

Large strain plane strain compression of this crystal develops the quasi-fibre texture illustrated in Figure $3 a$; after a strain of 1 this extends from (012)[02ī] to (021)[012] . 
Optical metallography does not reveal any obvious transition bands but clearly there must be a fairly high density of high lattice misorientation regions (this needs to be confirmed by TEM).

As above, annealing after a low strain develops a small number of large grains with virtually random orientations. Recrystallization after a strain of 1 leads to the sharp texture of Figure $3 \mathrm{~b}$ characterised by two components corresponding roughly to (023) $[\overline{2} 3 \overline{2}]$ and $(032)[22 \overline{3}]$ with a common [111] direction. These components can be obtained from the original (011)[011] orientation by rotations of $\pm 25-30^{\circ}$ about the common [111] pole, which is fairly consistent with the $30-40^{\circ}<111>$ relation typical of oriented growth (Note however that the 2 other variants obtained by similar rotations about the symmetric [i111] pole do not appear to occur in this case).

Recrystallization of this orientation therefore appears to support the oriented growth mechanism. Conclusive evidence does however require identification of the nucleation sites and orientations in this particular case since the deformed matrix appears to contain a high density of strongly misoriented regions on a scale which precludes observation by optical metallography.

\section{DISCUSSION AND CONCLUSIONS}

The three crystal orientations deformed in plane strain compression to strains of about 1 have quite different characteristics in terms of the deformation heterogeneities which constitute the potential nucleation sites

- the cube orientation develops a large number of transition bands in which nucleation of cube oriented germs takes place so that a strong cube texture is developed on complete recrystallization, (albeit with minor texture components typical of oriented growth).

- the (111)[112] orientation, by virtue of the formation of 1 transition band region in the centre of the specimen where nucleation can be expected, clearly favours oriented growth by the rate selection process during growth from the centre. The resulting recrystallization texture (111)[011] is in fact a good example of oriented growth after a $30^{\circ}$ rotation about the $[111]$ normal direction.

- finally the (011)[011̄] crystal which exhibits a wide range of orientations after deformation, and presumably a high density of potential nucleation sites, develops 2 variants of a texture obtained by rotations of $\sim \pm 30^{\circ}$ about a common [11i] pole. Although further work is necessary here to characterise the nucleation sites the general result tends to support the oriented growth model.

The above results pertain to relatively large strains $(\sim 1)$. At lower strains $(0,25)$ the density of nucleation sites is very much lower and so very few grains recrystallize (without a clearly-defined texture).

The general conclusion from these different initial orientations is that the controlling mechanism of recrystallization texture formation i.e. oriented growth or oriented nucleation, appears to depend upon the initial grain orientation ; oriented growth certainly makes a strong contribution unless there is a high density of transition bands.

The $30-40^{\circ}<111>$ relation between the growing recrystallized grain and the deformed matrix can be related to the special properties of the $\Sigma 7$ coincidence boundaries 
$\left(38,2^{\circ}\right.$ about $\left.<111>\right)$. Work is now in progress to determine the grain boundary character of all the recrystallized grains in the above samples.

\section{REFERENCES}

1. R.D.Doherty, J.Hirsch, W.B.Hutchinson, K.Lücke, E.Nes and P.J.Wilbrandt, ICOTOM 8, (Santa Fé, 1986), p. 563.

2. G.Ibe and K.Lücke, Recristallization Grain Growth and Textures (Ed. H. Margolin ASM, New York 1966) p.434.

3. K.Lücke, R.Rixen and M.Senna, Acta Metall., 24, 103 (1976).

4. A.Berger, P.J.Wilbrandt and P.Haasen, Acta Metall., 31, 1433 (1983).

5. A.Akef and J.Driver, Mat. Sci. Eng., in press.

6. G.C.Wonsiewicz and G.Y.Chin, Metall. Trans., 1, 57 (1970).

7. B.Orlans-Joliet, Doctoral Thesis, (ENSMSE, Saint-Etienne) 1989.

8. I.L.Dillamore and H.Katoh, Metal. Sci., 8, 73 (1974).

9. J.Hjelen and E.Nes, ICOTOM 8 (Santa Fé, 1986) p.597.
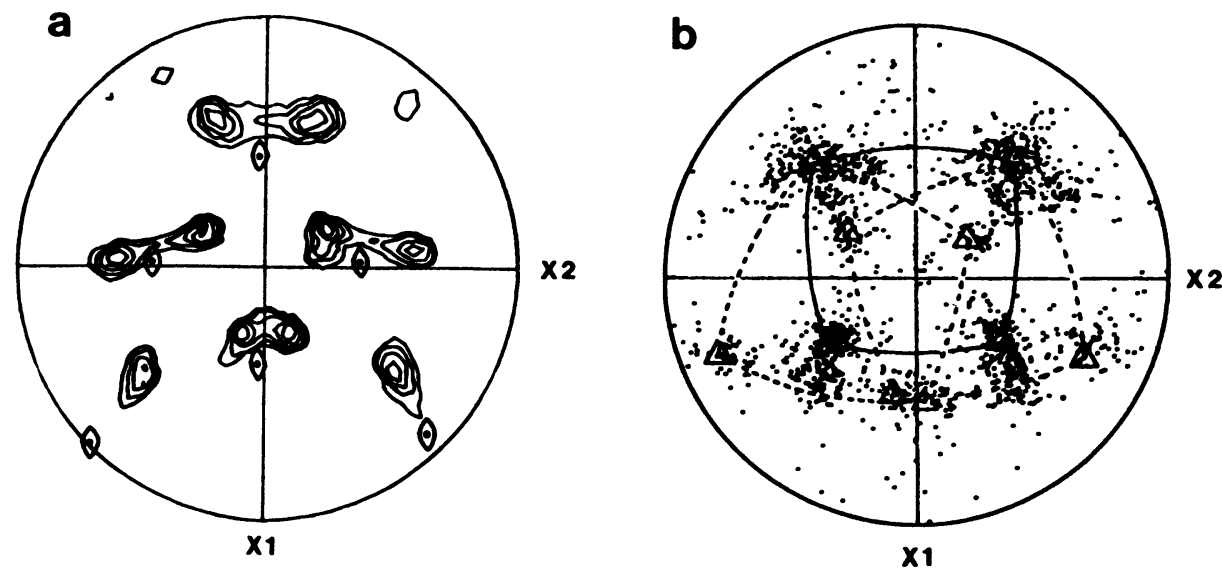

Figure 1. Deformed and recrystallized pole figures of the cube orientation.

a) $\{110\}$ poles of crystal at $\varepsilon=1, \diamond$ indicates initial $\{110\}$ pole positions ;

b) $\{111\}$ poles obtained by SACP on recrystallized grains of initial cube sample after $\varepsilon=1$ and $400^{\circ} \mathrm{C}$ anneal. 

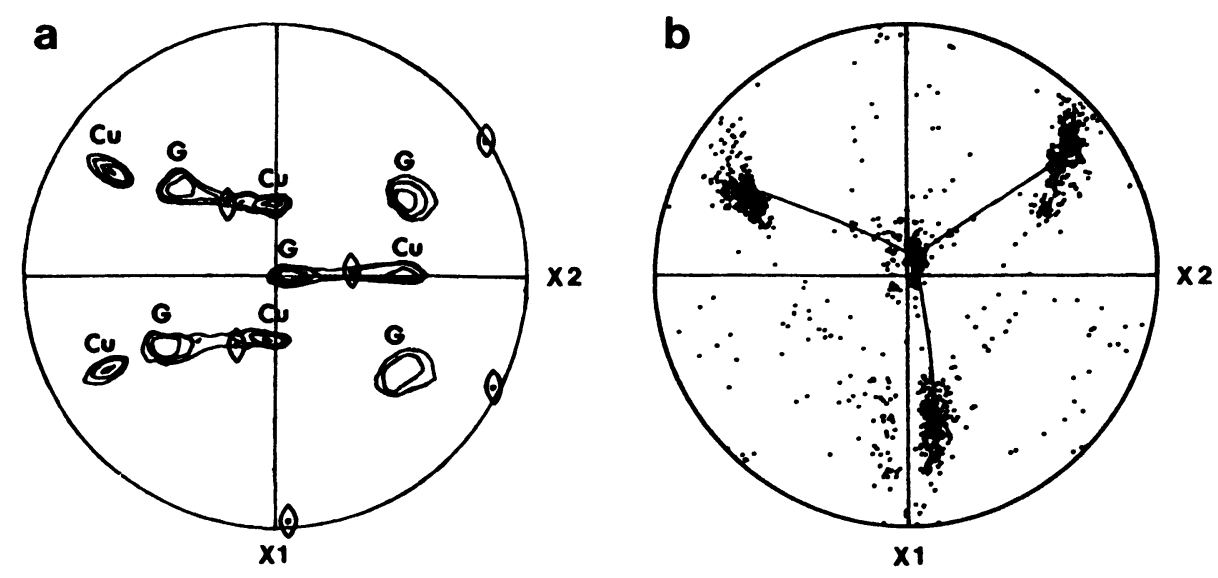

Figure 2. Deformed and recrystallized pole figures of the initial (111)[112̄] crystal.

a) $\{110\}$ poles at specimen centre, $\varepsilon=0,7$ showing both $\mathrm{Cu}$ and Goss components ;

b) $\{111\}$ poles obtained by SACP on recrystallized grains of (111)[112] crystal after $\varepsilon=0,7$ and $400^{\circ} \mathrm{C}$ anneal.
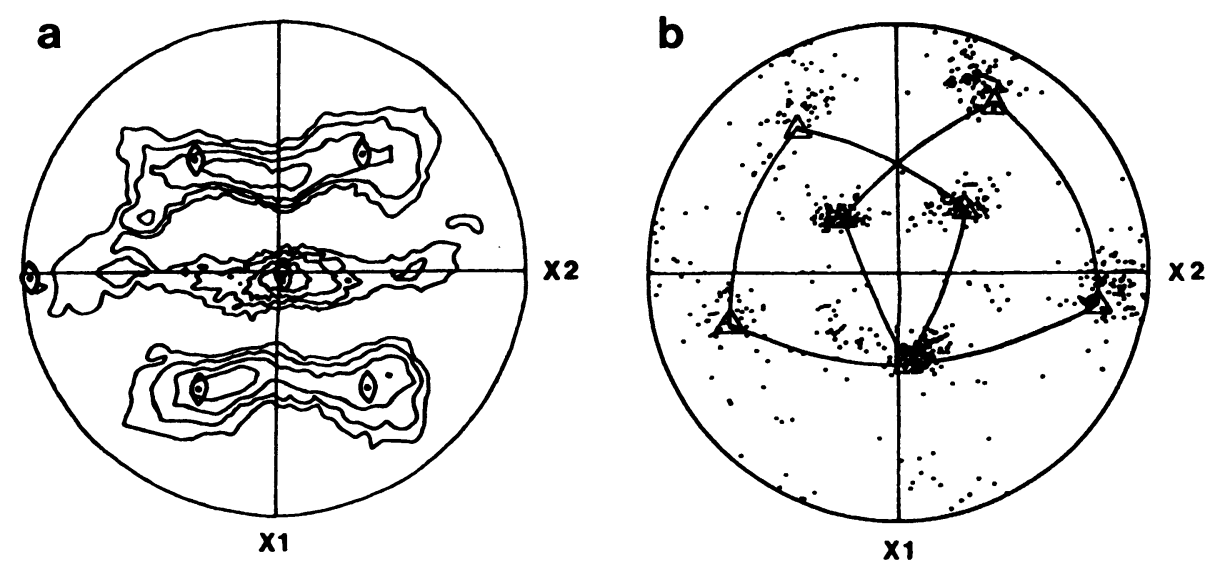

Figure 3. Deformed and recrystallized pole figures of the initial (011)[01i] crystal.

a) $\{110\}$ poles after $\varepsilon=1, \diamond$ indicates initial $\{110\}$ pole figures ;

b) $\{111\}$ poles obtained by SACP on recrystallized grains of (011)[111] crystal after $\varepsilon=1$ and $400^{\circ} \mathrm{C}$ anneal. 